\title{
Studies on the impact of the technical characteristics of local roads on road safety
}

\author{
Stanisław Gaca ${ }^{1,}$, and Mariusz Kieć ${ }^{1, *}$ \\ ${ }^{1}$ Cracow University of Technology, Faculty of Civil Engineering, Warszawska 24, 31-155 Krakow, Poland
}

\begin{abstract}
Local roads (district roads) constitute an important part of the road network in Poland, making up around $29.7 \%(124,945 \mathrm{~km})$ of all public roads. In $2017,10,578$ accidents, which is $35.7 \%$ of all accidents in Poland, took place on local roads. These roads are used primarily by regular users who are very familiar with the defects of these roads. This means that the effects of the low technical standard of local roads and the insufficient number of road traffic devices on the safety on the road can be partly compensated for by the fact that drivers adjust their behaviour to the conditions on the road. This hypothesis can be verified through developing dependency models of road safety measures of local roads' and technical characteristics. The article presents the research carried out based on regression models of accident prediction. The models were developed with the use of the data on the road surroundings arrangement (built-up areas, access), road condition and the extent of signposting, including data on speed limits and overtaking as well as risk exposure variables. Due to the incomplete data on accidents and the small number of accidents, different approaches to the modelling of the number of road accidents were applied.
\end{abstract}

\section{Introduction}

Local roads (district roads) constitute an important part of the road network in Poland, making up around $29.7 \%$ $(124,945 \mathrm{~km})$ of all public roads. In 2017, out of all road accidents in Poland, 10,578 of them took place on local roads, which is $35.7 \%$ of the total number. Local roads play a vital role in interconnecting small localities, connecting suburbs to city centers as well as providing a connection between regional and national roads. Usually, they have low geometric parameters (low design speed determining design parameters) and are equipped with a necessary minimum number of traffic organization and safety measures. At the same time, drivers using these roads move at high speeds; it is estimated that over $60 \%$ of vehicles exceed the maximum speed in built-up areas and approximately $25 \%$ - outside built up areas. What is characteristic about local roads is a low traffic volume, except for roads in suburban areas.

District roads are mainly used by local drivers who are well aware of the defects of these roads. This means that the effects of the low technical standard of local roads and the insufficient number of road traffic devices on the safety on the road can be partly compensated for by the fact that drivers adjust their behaviour to the conditions on the road. To verify this hypothesis, the Authors developed models of road safety measures and technical characteristics of local roads. If the role of these characteristics among the exogenous variables (including risk exposure variables) turns out to be secondary, there will be no grounds for rejecting the hypothesis set out above. However, the reasoning as such may raise some doubts as to whether the data available are sufficient to create statistically significant models capable of describing the relationship between direct measures of road safety (collisions, accidents, victims) and technical characteristics of local roads. Due to the regional character of spatial development and diversification in the shape of local roads, regression models should be created specifically for a given region. Therefore, obtaining a considerable amount of data is limited. In general, the amount of data is limited due to the fact that accidents are randomly dispersed in the network of local roads. This becomes evident when comparing the average density of accidents on roads of different categories. In the case of national roads, the average density of accidents is 0.39 accident $/ 1 \mathrm{~km}$, on regional roads -0.21 accident $/ 1 \mathrm{~km}$ and on district roads - 0.085 accident $/ 1 \mathrm{~km}$. Most importantly, the nature of road safety analysis is determined by the lack of access to the precise details on the accident location; usually only data on the section of the road is given. From numerous expert assessments, including safety inspections of local roads, it was found that the concentration of accidents on local roads is more often linked to the exposure to risk measures rather than to the technical characteristics of roads.

All things considered, the primary objective of this study is framed by the following questions: "To what extent do technical characteristics of local roads affect the

* Corresponding author: mkiec@pk.edu.pl 
road safety?" and "Can this safety be sufficiently assessed by number of accidents?" Answering these questions is crucial for the planning of measures aiming at improving the road safety and the development of methods facilitating the identification of places and sections on local roads with a high potential risk.

As part of the research, the Authors have carried out a road safety analysis for district roads in southern Poland. In the Małopolska region, the analysis included district roads of a total length of $575.7 \mathrm{~km}$ where, within 4 years (2010-2013), 665 accidents were registered. In the Podkarpacie region, the analysis took into account 572.6 $\mathrm{km}$ of district roads where, within 4 years (2012-2015), 243 accidents were registered (133 - outside cities). These data seem to confirm a significant region-specific diversification in road safety on district roads. For selected road sections from the Małopolska region (20 sections with a total length of $165.08 \mathrm{~km}$ ), a detailed inventory of the existing condition was carried out, including geometrical road parameters (deflection, curve radius, longitudinal slopes, roadway width, location of intersections). It was made possible with the help of GPS tools which are efficient at collecting data. The collected data concerned the arrangement of the areas adjacent to analysed roads (built-up areas, access), condition, frequency and extent of signposting, as well as data on speed limits and overtaking limits. The collected data was used for the construction of accident prediction models. Due to the limitations of the database on accidents and small number of accidents, different approaches to the modelling of road accident numbers were applied.

\section{Literature review}

The issue of road safety on local roads is rarely discussed in Polish articles. Due to their parameters, low technical class roads in Poland correspond to what foreign literature describes as low volume roads (LVR) in terms of their design and use. Most often road safety is expressed through accident prediction models describing the impact of traffic volume and road characteristics on the frequency of accidents. LVR roads are single carriageway two-lane roads with a traffic volume limit ranging from 100 to $6000 \mathrm{Veh} / 24 \mathrm{~h}$, where in the majority of the analysed countries this scope ranges from 400 to 2000 $\mathrm{Veh} / 24 \mathrm{~h}[1,2]$. At the same time, these roads constitute a significant part of country roads (roads outside built-up areas), which corresponds to $50 \%$ in the Netherlands, Denmark, and Norway; 70\%-90\% in Australia, Belgium, Canada, Finland, and Spain

Foreign literature discusses numerous accident prediction models for LVR roads, which allow to estimate the number of accidents or accident rates [5]. It is often the case that variables describing road features are considered statistically significant in the accident prediction models. Among the investigated features are the following: the width of the traffic lane, shoulder width, the share of different types of shoulders (paved and unpaved), superelevation, curvature, design consistency. Road safety researches on LVR roads in Israel [6], and the USA [4] show that values of accident rates are higher in comparison to other local roads. Literature often describes this phenomenon as the defect of an accident rates (number of accidents per million vehicle kilometers) when used in the description of the real risk of accidents and identification of dangerous sites [7].

Numerous studies indicate that factors identifiable as statistically significant in the accident prediction models on LVR are: geometric parameters of road plan [6], design consistency [8, 9], traffic volume [3, 10], geometric parameters of the cross section $[9,11,12]$, and average speed [9]. In addition to this, the terrain level is sometimes indicated as having an impact on accidents on LVR roads [9], i.e. there is a different impact on flat, rolling or mountainous terrain. Valuable results in terms of the design requirements for LVR are shown in [13]. The recommended values for geometrical parameters for LVR, having statistical significance in improving road safety, require the following: shoulder width up to $3 \mathrm{~m}$, increase in lane width up to $3.2 \mathrm{~m}$, reduced number of horizontal curves with a radius below $300 \mathrm{~m}$, creating "forgiving" cross sections of roads or barriers, warnings on the approach to large longitudinal slopes. They confirm the findings in $[11,12]$, which indicate that extending the lane and the shoulder result in a decrease in the number of accidents. However, these recommendations can be difficult to implement in Poland as the cited parameters correspond to Polish regional roads. Local roads in Poland usually connect localities that are situated in close proximity to each other and average travel times on these routes are quite short. Therefore, drivers' expectations regarding the travel comfort on such roads are lower.

Accident prediction models usually include variables representing the risk exposure (traffic volume) and the geometric features of roads. However, the scope of exogenous variables in various models varies depending on the sections selected for analysis, the availability of the input data and the type of analysis. This means that there is no clarity as to the set of geometric characteristics of low volume roads which affect the number of accidents estimated by prediction models.

What resulted from the road safety analysis on LVR are practical recommendations on the application of selected measures to improve road safety [3]. Among these measures are: bigger warning signs, additional signs with a maximum safe speed, single chevrons as well as guideposts on curves requiring reducing speed, the application of edge lines on LVR roads with speed reduced to $70 \mathrm{~km} / \mathrm{h}$ and less, and a centerline on roads with a width exceeding $5.5 \mathrm{~m}$. The use of acoustic decelerating speed bumps is recommended on the approach to intersection entries. It should also be considered on the approach to horizontal curves requiring more aggressive road marking. There are suggestions to design roads with a lane of the roadway of at least $3 \mathrm{~m}$ and shoulders of at least $0.6 \mathrm{~m}$. These recommendations clearly suggest a strong influence of technical characteristics of LVRs and road signposting and marking on road safety. However, there is insufficient evidence whether such recommendations should also be introduced in Poland, especially in view of the thesis about regular LVR users and the adjustment of the driving style to the 
low standard of the road (which makes sense only in the case of drivers with a good knowledge of the route). Therefore, the overview of the available literature suggests a need to take up similar studies in Poland, seeing as nothing in this matter has ever been done.

\section{Characteristics of low volume roads in Poland}

Local roads in Poland have, as is in other countries, low geometrical parameters, in particular [14]:

- low traffic volume, rarely exceeding $2000 \mathrm{Veh} / 24 \mathrm{~h}$ (SDR). Regular road users with a good knowledge of particular road sections;

- high traffic volume occurring locally and specific to suburban areas

- heterogeneous nature of the road plan - long tangents with sections of considerable curvature

- roadways 5.5-6.0 m wide with narrow ground shoulders up to $1.0 \mathrm{~m}$ wide.

- absence of or low standard of horizontal marking;

- heavy pedestrian traffic occurring locally;

- average speed limit of $90 \mathrm{~km} / \mathrm{h}$ outside built-up areas and $50 / 60 \mathrm{~km} / \mathrm{h}$ in built-up areas; lack of connection between the choice of road technical parameters and the maximum speed limits;

- presence of road elements designed for roads with low speed $40-50 \mathrm{~km} / \mathrm{h}$ ); no requirements regarding to the control of geometric consistency of roads;

- a large share of road sections with built-up areas.

The design parameters of curves, which are predominantly used on local roads, result in a large dispersion of speed on subsequent homogenous sections. Low traffic volume encourages drivers to exceed speed limits even on very narrow sections of roads $[14,15]$.

\section{The accident and road database}

The preliminary road safety analysis aiming at identifying problems was carried out in the Małopolska region on local roads with the total length of $575.69 \mathrm{~km}$. During 4 years (2010-2013), 665 accidents were registered on those roads. The analyses made use of the data on accidents available from the SEWiK accidents and collisions database. Based on the police records, specifically police accident reports, it was concluded that:

- the average density of accidents amounts to 0.25 accident $/ \mathrm{km} /$ year,

$-77 \%$ of accidents took place in built-up areas (i.e. ca $6 \%$ more than the average for Polish roads in general in 2017)

$-31.4 \%$ of accidents took place on curved sections of the road and $48.5 \%$ on tangents ones (i.e. ca $20 \%$ more and $8 \%$ less than the average for Polish roads in 2017, respectively)

$-11 \%$ of accidents resulted from poor road maintenance (less than $0.1 \%$ accidents occur on higher class roads);

$-11 \%$ of accidents took place on unlit roads (i.e. ca $3 \%$ more than the average for Polish roads).
- Among the most frequent incidents were side collisions $(22.86 \%)$ and hitting a pedestrian $(21.5 \%)$ - comparing to the average for Polish roads 2017 the share of these values amounted to $24.1 \%$ and $30 \%$, respectively.

- The most common cause of accidents was speed inadequate to the traffic conditions - 31\%, the average for Polish roads for $2017-24.1 \%$, and ignoring a rightof-way rule - $16.7 \%$, the average for Poland in 2017 $26.2 \%$ ).

The statistical results presented above regarding road safety on local roads are similar to those for the Podkarpacie region in terms of the structure and causes of accidents. However, there is a substantial difference as to the density of accidents which, on the roads of the Leżajsk and Przeworsk counties amount to 0.106 accident $/ \mathrm{km} /$ year, i.e. two times less than in the Malopolska region. Such a difference may arise from smaller traffic volumes in the Podkarpacie region.

Accident statistics presented for analysis indicate such problems as: inconsistency in the road design, excessive speed and access. An important factor is the location of the road section. All of these observations have been taken into account in the selection of the research sample consisting of 20 road sections from the Kraków county, and in the selection of exogenous variables as part of creating regression models for estimating the numbers of accidents on district roads.

The 20 road sections selected for investigation (Fig. 1) have the total length of $165.08 \mathrm{~km}$. A detailed inventory of the current condition of the selected segments was carried out and the following geometrical parameters were specified: deflection, curve radius, longitudinal slope, roadway width. For this purpose, a GPS-based devices was used, , which provides an instant feedback when collecting data on location in high frequency (10 $\mathrm{Hz}$ ). The results of the GPS measurements were used to designate the geometrical parameters of the route, including the length of tangents, curves radii, deflection and longitudinal slopes, in AutoCad Civil 3D software. Each of the selected district roads was video recorded. Based on the recordings, the following were identified: factors related to the arrangement of the areas adjacent to roads (built-up areas, access) together with their signposting and marking, technical condition of the road as well as data on speed limits and overtaking restrictions. The data collected helped develop accident regression models. Due to the unavailability of the complete data on accidents (no data on the exact location of accidents) and a small number of these events, 3 different approaches were tested in the construction of regression models. 


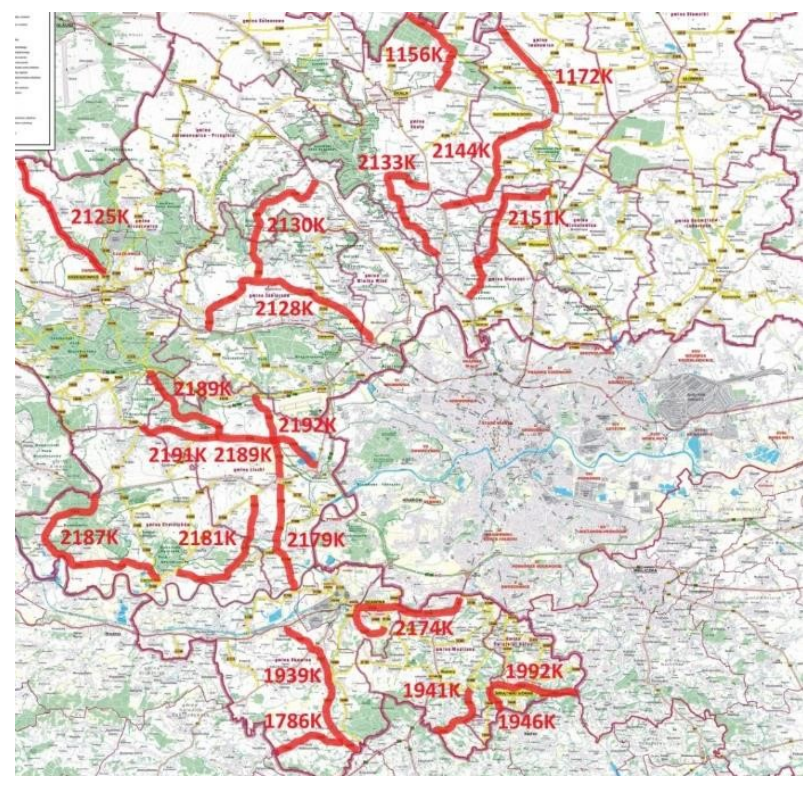

Fig. 1. Location of district roads in the Małopolska region used for developing accident prediction models.

\section{Research method}

One of the methods to describe road safety is developing accident regression models. As indicated in the literature [9], various regression models can be used to estimate the number of accidents on LVR. One of the recommended methods for rare events and a large dispersion of accident numbers are negative binomial regression models [16]. This was the method used in the present analyses, and the following general form of a regression model was assumed:

$L W=S D^{a} \cdot L^{b} \cdot e^{\left(c+\sum_{i}^{n} d_{i} \cdot x_{i}\right)}$

where:

$L W$ - the average number of accidents on a road section, $S D R$ - average annual daily traffic [veh/24 h] on a road section,

$L$ - length of the section [km],

$x_{i}-$ an independent variables in the model,

$a, b, c, d_{i}$ - regression coefficients.

In the analyses, the number of accidents in 4-years period was selected as the dependent variable. For this variable, models were developed by selecting as independent variables: variables that describe risk traffic volume $(S D R)$ and length of the section $(L)$, as well as variables describing the technical and functional characteristics of the road. These variables are summarised in tables 1-4.

Initially, the selected significance level allowing for the introduction of a variable to the model equalled $95 \%$, but in some cases it got lowered to $90 \%$, which reduces the accuracy of the model. This procedure allowed, however, for the introduction to the model of a larger set of exogenous variables.

Regression models were developed using IBM SPSS Statistics 20. For comparison purposes, three approaches were carried out in order to identify factors that could significantly affect the value of the exogenous dependent variable. Regression models were developed for homogeneous sections with the following approaches:

- Approach 1: In addition to the basic variables of risk exposure, i.e. $S D R$ and $L$, also the qualitative variable of location (built-up area and non-built-up area) (Table 1) was included in the model.

- Approach 2: The developing of separate models for road sections in built-up and non-built-up areas (Tables 2 and 3)

- Approach 3: The developing of models for the whole sample of district roads' sections - non divided into homogenous sections (Table 4)

\section{Accident prediction models for LVR}

Tables 1-4 summarise the independent variables that were tested in the developing of regression models along with their variation range (minimum and maximum values), the mean value and standard deviation). The variables that were analysed as independent variables were related to: the geometry of the section (curvature of the segment), access to the road (the intersection density), location (built-up area and non-built-up area or their share). Other variables such as: lane width, width and type of shoulder, longitudinal slopes, have been found to be statistically insignificant and do not appear in the developed models.

Table 1. Descriptive statistics of the variables used to develop models - approach 1.

\begin{tabular}{|c|c|c|c|c|}
\hline Variable & $\min$ & $\max$ & average & std. dev. \\
\hline $\begin{array}{l}\text { Traffic volume } \\
S D R \text { [Veh/24h] }\end{array}$ & 883 & 19,352 & $6,734.5$ & 5,092 \\
\hline $\begin{array}{l}\text { Length of the section } \\
L[\mathrm{~m}]\end{array}$ & 0.19 & 8.28 & 2.26 & 1.89 \\
\hline $\begin{array}{l}\text { Sum of deflection } \\
\text { kat } z w\left[{ }^{\circ}\right]\end{array}$ & 0 & $1,867.37$ & 341.59 & 371.50 \\
\hline $\begin{array}{l}\text { Curvature of the } \\
\text { section } \\
\mathrm{Cuv}\left[{ }^{\circ} / \mathrm{km}\right]\end{array}$ & 0 & 480.97 & 144.52 & 99.97 \\
\hline $\begin{array}{l}\text { Density of } \\
\text { intersections Gsk } \\
{[\mathrm{sk} / \mathrm{km}]}\end{array}$ & 0 & 3.39 & 1.07 & 0.88 \\
\hline $\begin{array}{l}\text { Number of accidents } \\
L W 2010-2013\end{array}$ & 0 & 16 & 3.55 & \\
\hline
\end{tabular}
(nzab) (YES/NO) 
Table 2. Descriptive statistics of the variables used to develop models, built-up area - approach 2.

\begin{tabular}{|l|c|c|c|c|}
\hline Variable & $\min$ & $\max$ & average & std. dev. \\
\hline $\begin{array}{l}\text { Traffic volume } \\
S D R[\text { Veh/24h] }\end{array}$ & 883 & 19,352 & $6,853.48$ & $5,304.39$ \\
\hline $\begin{array}{l}\text { Length of the section } \\
L[\mathrm{~m}]\end{array}$ & 0.19 & 8.28 & 2.93 & 2.21 \\
\hline $\begin{array}{l}\text { Sum of deflection } \\
k a t z w\left[^{\circ}\right]\end{array}$ & 0 & $1,867.37$ & 452.41 & 416.96 \\
\hline $\begin{array}{l}\text { Curvature of the } \\
\text { section } \\
C u v[\% / k m]\end{array}$ & 0 & 387.59 & 157.39 & 100.07 \\
\hline $\begin{array}{l}\text { Density of } \\
\text { intersections } G s k \\
{[\text { sk/km] }}\end{array}$ & 0 & 3.39 & 1.38 & 0.83 \\
\hline $\begin{array}{l}\text { Number of accidents } \\
L W 2010-2013\end{array}$ & 0 & 16 & 3.55 & \\
\hline
\end{tabular}

Table 3. Descriptive statistics of the variables used to develop models, non built-up area - approach 2 .

\begin{tabular}{|l|c|c|c|c|}
\hline Variable & $\min$ & $\max$ & average & std. dev. \\
\hline $\begin{array}{l}\text { Traffic volume } \\
S D R[\text { Veh/24h] }\end{array}$ & 883 & 19,352 & $6,573.26$ & $4,871.22$ \\
\hline $\begin{array}{l}\text { Length of the section } \\
L[\mathrm{~m}]\end{array}$ & 0.45 & 3.10 & 1.35 & 0.67 \\
\hline $\begin{array}{l}\text { Sum of deflection } \\
k a t z w\left[^{\circ}\right]\end{array}$ & 4.62 & $1,219.74$ & 191.44 & 230.50 \\
\hline $\begin{array}{l}\text { Curvature of the } \\
\text { section } \\
C u v\left[^{\circ} / \mathrm{km}\right]\end{array}$ & 6.02 & 480.97 & 127.10 & 98.78 \\
\hline $\begin{array}{l}\text { Density of } \\
\text { intersections Gsk } \\
{[\text { sk/km] }}\end{array}$ & 0 & 3.26 & 0.66 & 0.77 \\
\hline $\begin{array}{l}\text { Number of accidents } \\
L W 2010-2013\end{array}$ & 0 & 3 & 0.97 & \\
\hline sample size: 31 sections in non built-up area (nzab) & & \\
\hline
\end{tabular}

Table 4. Descriptive statistics of the variables used to develop models - approach 3 .

\begin{tabular}{|c|c|c|c|c|}
\hline Variable & $\min$ & $\max$ & average & std. dev. \\
\hline $\begin{array}{l}\text { Traffic volume } \\
S D R \text { [Veh/24h] }\end{array}$ & 883 & 19,352 & $6,445.10$ & $5,502.49$ \\
\hline $\begin{array}{l}\text { Length of the section } \\
L[\mathrm{~m}]\end{array}$ & 3.08 & 13.11 & 8.24 & 2.86 \\
\hline $\begin{array}{l}\text { Share of section in the } \\
\text { built-up area Uzab [-] }\end{array}$ & 0.36 & 1.00 & 0.76 & 0.19 \\
\hline $\begin{array}{l}\text { Sum of deflection } \\
\text { kat } z w\left[^{\circ}\right]\end{array}$ & 370.25 & $2,164.47$ & $1,246.81$ & 561.09 \\
\hline $\begin{array}{l}\text { Curvature of the section } \\
\mathrm{Cuv}\left[{ }^{\circ} / \mathrm{km}\right]\end{array}$ & 80.55 & 317.26 & 152.90 & 57.99 \\
\hline $\begin{array}{l}\text { Density of intersections } \\
G s k[\mathrm{sk} / \mathrm{km}]\end{array}$ & 0.61 & 3.25 & 1.30 & 0.61 \\
\hline $\begin{array}{l}\text { Number of accidents } \\
L W 2010-2013\end{array}$ & 3 & 25 & 8.95 & \\
\hline
\end{tabular}

sample size: 20 sections

Below are presented the obtained regression models for estimating the number of accidents at different approaches to the developing of these models. Also provided are the values of: regression coefficients, standard error and significance level, the Wald Chisquared Test, as well as the values of statistical significance of the analysed variable. The comparison of the models was carried out based on the Akaike information criterion (AIC).

\subsection{Approach 1}

Including in the model, in addition to variables $S D R$ and $L$, also the qualitative variable of location $(z a b / n z a b)$ resulted in a model of the following form:

$$
L W=S D R^{0,225} \cdot L^{0,683} \cdot \exp ^{(-2,112 \cdot n z a b-1,311 \cdot z a b)}(2)
$$

variables marked in the model according to the description in Table 1. In the case of the qualitative variable of location type, one should assume the value of 1 (if present), or 0 if not present.

In the model, the variables which proved to be statistically significant were the variables of risk exposure, SDR and $L$, and the qualitative variable of location. The model was developed with zero intercept due to its lack of statistical significance. Other variables have been removed from the model due to the low level of significance, which can be interpreted as a lack of the statistical effect of these variables on the estimated value of the number of accidents. The statistical evaluation of the model was presented in Table 5.

Table 5. Evaluation of the parameters for the model approach 1.

\begin{tabular}{|c|c|c|c|c|c|}
\hline & & $\ln S D R$ & $L n L$ & $\begin{array}{c}\text { location }= \\
n z a b\end{array}$ & $\begin{array}{c}\text { location }= \\
z a b\end{array}$ \\
\hline \multicolumn{2}{|l|}{ coefficient } & 0.225 & 0.683 & -2.112 & -1.311 \\
\hline \multicolumn{2}{|c|}{ standard error } & .1290 & 0.1648 & 1.1332 & 1.1356 \\
\hline \multirow{2}{*}{$\begin{array}{l}\text { Wald } 95 \% \\
\text { confidence } \\
\text { interval }\end{array}$} & $\begin{array}{l}\text { lower } \\
\text { limit }\end{array}$ & -0.028 & 0.360 & -4.333 & -3.537 \\
\hline & $\begin{array}{l}\text { upper } \\
\text { limit }\end{array}$ & 0.478 & 1.006 & 0.109 & 0.915 \\
\hline $\begin{array}{l}\text { Hypothesis } \\
\text { test }\end{array}$ & \begin{tabular}{|l|} 
Wald \\
Chi- \\
squared
\end{tabular} & 3.035 & 17.178 & 3.475 & 1.333 \\
\hline \multicolumn{2}{|c|}{ Significance } & 0.081 & 0.000 & 0.062 & 0.248 \\
\hline
\end{tabular}

The developed model confirms the high (statistically significant) impact of the length of the section on the number of accidents and a lower impact of traffic volume on the number of accidents. The number of accidents in built-up areas with respect to non-built-up area of the same section length is 2.2 times higher. Consideration should be given to the high value of the statistical significance of the coefficient with the variable $S D R$ equal to 0.081 , reflecting the low significance of the impact of SDR on the number of accidents.

\subsection{Approach 2}

In the second approach, the available data set was divided into two sets of roads: located in built-up areas and outside of them.

The conducted analyses allowed to develop a statistically significant model only for the set of sections from the built-up area. The obtained model was as follows:

$$
L W=S D R^{0,331} \cdot L^{0,664} \cdot \exp ^{(-2,284)}
$$

variables marked in the model according to the description in Table 2. 
In the model, the only variables which proved to be statistically significant were the variables of risk exposure, $S D R$ and $L$ and intercept. Other variables have been removed from the model due to the low level of significance, which can be interpreted as a lack of the statistical effect of these variables on the estimated value of the number of accidents. The statistical evaluation of the model was presented in Table 6.

Similarly to the model for approach 1 , the low value of the regression coefficient with the variable $S D R$ indicates a lower impact of traffic volume in the explanation of the number of accidents than length of section.

Table 6. Evaluation of the parameters for the model approach 2.

\begin{tabular}{|l|l|c|c|c|}
\hline \multicolumn{2}{|l|}{} & intercept & InSDR & LnL \\
\hline coefficient & -2.284 & 0.331 & 0.664 \\
\hline standard error & 1.2112 & 0.1376 & 0.1666 \\
\hline \multirow{2}{*}{$\begin{array}{l}\text { Wald 95\% } \\
\text { confidence } \\
\text { interval }\end{array}$} & $\begin{array}{l}\text { lower } \\
\text { limit }\end{array}$ & -4.658 & 0.062 & 0.338 \\
\cline { 2 - 5 } & $\begin{array}{l}\text { upper } \\
\text { limit }\end{array}$ & 0.090 & 0.601 & 0.991 \\
\hline $\begin{array}{l}\text { Hypothesis } \\
\text { test }\end{array}$ & $\begin{array}{l}\text { Wald Chi- } \\
\text { squared }\end{array}$ & 3.556 & 5.800 & 15.898 \\
\hline \multicolumn{2}{|l|}{ Significance } & 0.059 & 0.000 & 0.000 \\
\hline
\end{tabular}

Comparison the values of the Akaike information criterion (AIC) indicates a better fit of the model than in the case of approach 1 .

\subsection{Approach 3}

In this approach, the entire set of local roads was analysed, without dividing them into homogenous sections. Such an approach allows in practice to build databases on roads and accidents more easily, given the lack of information on the exact location of accidents in police databases. The conducted analyses have made it possible to create the following model:

$$
L W=S D R^{1,414} \cdot L \cdot \exp ^{(-17,582+2,839 \cdot U z a b)}
$$

variables marked in the model according to the description in Table 4.

In this model, the variables which proved to be statistically significant were the variables of risk exposure, $S D R$ and $L$, and the variables of the share of road sections in built-up areas as well as intercept. The remaining variables have been removed from the model due to the low level of significance, which can be interpreted as a lack of the statistical effect of these variables on the estimated number of accidents.

In the case of approach 3, only one parameter describing road infrastructure has turned out to be significant, i.e. the length of roads in built-up areas. This variable describes mainly the impact of the intensity and management of the road surroundings, including the presence of pedestrian and bicycle traffic, access roads from surrounding buildings, local travel on short distances, etc. In approaches 1 and 2, this specific character of the traffic on sections with buildings was also accounted for by the qualitative variables - built-up areas $(z a b)$, non-built-up areas $(n z a b)$. The significance level values of the exogenous variables in the model show a large dispersion of the results and a relatively low level of statistically significance of the independent variable. The statistical evaluation of the model was presented in Table 7.

Table 7. Evaluation of the parameters for the model approach 3.

\begin{tabular}{|l|c|c|c|c|}
\hline \multicolumn{2}{|l|}{} & intercept & InSDR & LnL \\
\hline coefficient & -17.582 & 1.414 & 2.839 \\
\hline \multicolumn{2}{|l|}{ standard error } & 6.7645 & 0.7823 & 1.7618 \\
\hline $\begin{array}{l}\text { Wald 95\% } \\
\text { confidence } \\
\text { interval }\end{array}$ & lower limit & -30.840 & -0.119 & -0.614 \\
\cline { 2 - 5 } & upper limit & -4.324 & 2.947 & 6.292 \\
\hline $\begin{array}{l}\text { Hypothesis } \\
\text { test }\end{array}$ & $\begin{array}{l}\text { Wald Chi- } \\
\text { squared }\end{array}$ & 6.756 & 3.268 & 2.597 \\
\hline \multicolumn{2}{|l|}{ Significance } & 0.009 & 0.071 & 0.100 \\
\hline
\end{tabular}

The value of the Akaike Information Criterion (AIC) indicates a better fit of the model than in the case of approach 1, but a worse one than in the case of approach 2. What is also surprising is the low impact of traffic volume on the estimated number of accidents.

A general comparison of the three applied approaches to developing regression models for the number of accidents on local roads shows that in none of the approaches used did independent variables describing geometrical parameters turn out to be statistically significant. What did find confirmation was the significant impact of the manner in which the road surroundings are managed (sections in built-up areas) and the impact of variables describing the risk exposure.

The models described above were developed based on a limited set of road sections and, therefore, the results of the analyses should be considered preliminary. However, they point to the merits of the construction of models separately for road sections in built-up areas and outside these areas.

\section{Conclusions}

The statistical analysis of accident data on local roads clearly showed that road sections with the highest safety risk are located in built-up areas. Most accidents take place in built up areas where tangents are present. In such cases, the accident cause is connected to excessive speed. If the speed is inadequate to the traffic conditions, the vehicle may ran off the roadway on a horizontal curve. Poor road maintenance is another important factor generating accidents on local roads. The distribution of accidents in the road network indicates a small number of places with higher density of accidents. If any, the places of this kind can be identified on road sections located in the vicinity of larger urban centres (high traffic volume). From the data collected as part of the detailed inventory, it was concluded that local roads have segments with plenty of defects putting drivers' safety at risk. However, these were not segments where accidents occur more often. This suggests that in the case of LVR, there is a need to use also other measures than accident factor when identifying road segments with high accident potential. 
This brings us to the conclusion that surrogate safety measures, especially speed and its dispersion, should also be taken into account. Doing so will facilitate the introduction of solutions aiming at increasing the road safety in a proactive manner. The inventory of roads suggests that providing more information about the poor technical standard of certain road segments may be an effective measure protecting drivers against traffic risks on LVR.

Simple analyses on the change of road accident number in relation to geometrical characteristics of local roads have revealed that the increase in the number of accidents is linked to the growing density of development and the increase in the density of access points. The analysis of accidents in relation to road curvature suggested that the increase in the road curvature corresponds to the growing road safety (due to the decrease in speed). This relationship has not yet been reflected in the regression models developed, including, apart from the risk exposure variables, also variables describing the geometry of roads.

The developed regression models estimating the number of accidents indicate that the predominant factors influencing the road safety on local roads are risk exposure variables, i.e. the length of the road segment and, to a lesser extent, the traffic volume. From among infrastructure variables, the presence of built-up area in the surroundings of the road is an important factor. This factor may also be treated as indirectly describing the risk exposure. The development affects the intensity and manner of operation of the road surroundings, including the presence of pedestrians and cyclists as well as access to roads from the properties surrounding the road, or locals travelling on short distances.

Various approaches applied in modelling suggest that using long segments, which facilitates the collection of data, does not give satisfactory results. What seems to be more helpful is to single out homogeneous road sections from road segments and analyse them in the context of the data on accidents. However, this is difficult due to the insufficient data on accident locations.

The absence of independent variables in the created models describing the impact of the geometrical characteristics of the road on the number of accidents can be treated as a preliminary confirmation of the hypothesis that road safety on local roads depends heavily on drivers' familiarity with the road.

\section{References}

1. Economic design of low-traffic roads, Organization for Economic Co-operation and Development, Paris; (OECD, 1986)

2. TRB, Eight International Conference on LowVolume Roads 2003, Transp. Res. Record 1819 (2003)

3. J.W. Hall, E.W. Rutman, J.D. Brogan, Highway Safety Challenges on Low-Volume Rural Roads. Final Report, (Federal Highway Administration, New Mexico Division, 2002)
4. N. Stamatiadis, S. Jones, L. Aultman-Hall. Causal Factors for Accidents on Southeastern Low-Volume Rural Roads. Transp. Res. Record 1652 pp. 111-117 (1999)

5. M. Reurings, T. Janssen, R. Eenink, R. Elvik, J. Cardoso, C. Stefan, Accident prediction models and road safety impact assessment: a state-of-the-art, RIPCORD-ISEREST research project (2005)

6. S. Hakkert, L. Shokir-Hadad, The impact of infrastructure of local rural roads on road accidents, Research Report 318-2009, (Transportation Research Institute 2009)

7. D. T. Silcock, A.W. Smyth, Methods of Identifying Accidents Blackspots, Transport Operations Research Group, Department of Civil Engineering, University Of Newcastle Upon Tyne (1985)

8. C. Mattar-Habib, A. Polus, H. Farah, Further evaluation of the relationship between enhanced consistency model and safety of two-lane rural roads in Israel and Germany. Eur. J. Transp. Infrast. 8(4) pp. 320-332 (2008)

9. G. Dell'Acqua, F. Russo, Safety performance functions for low-volume roads (TRB Annual Meeting Compendium of Papers, Transportation Research Board; 2011)

10. A. Polus, M. Cohen, Models of Accidents on LowVolume Rural Roads, (TRB Annual Meeting Compendium of Papers, Transportation Research Board; 2010)

11. C. V. Zegeer, R. C. Deen, J. G. Mayes, Effect of Lane Width and Shoulders Width on Accident Reduction on Rural Two-lane Roads, Transp. Res. Record 806 pp. 33-43 (1981)

12. D. W. Harwood, F. M. Council, E. Hauer, W. E. Hughes, and A. Vogt, Prediction of the Expected Safety Performance of Rural Two-lane Highways. Publication No FHWA-RD-99-207, (Federal Highway Administration, 2000)

13. V. Gitelman, E. Doveh, R. Carmel, F. Pesahov, The relationship between road accidents and infrastructure characteristics of low-volume roads in Israel, Proceedings of Second International Conference on Traffic and Transport Engineering (ICTTE), pp 350-358 (2014)

14. S. Gaca, M. Kiec, Speed Management for Local and Regional Rural Roads, Transp. Res. Proc. 14 pp. 4170-4179 (2016),

15. http://www.krbrd.gov.pl/pl/monitoringzachowan.html (05.2018)

16. S.-P. Miaou, P. S. Hu, T. Wright, A. K. Rathi, S. C. Davis. Relationship Between Truck Accidents and Highway Geometric Design: A Poisson Regression Approach. Transp. Res. Record 1376 pp. 10-18 (1992) 